\title{
Limitation of radiological T3 subclassification of rectal cancer due to paucity of mesorectal fat in Chinese patients
}

\author{
Esther MF Wong *, Bill MH Lai, Vincent KP Fung, Hester YS Cheung, WT Ng, Ada LY Law, Alta YT Lai, \\ Jennifer LS Khoo
}

\section{A B S T R A C T}

Objectives: To describe the thickness of mesorectal fat in local Chinese population and its impact on rectal cancer staging.

Design: Case series.

Setting: Two local regional hospitals in Hong Kong.

Patients: Consecutive patients referred for multidisciplinary board meetings from January to October 2012 were selected.

Main outcome measures: Reports of cases that had undergone staging magnetic resonance imaging for histologically proven rectal cancer were retrospectively retrieved and reviewed by two radiologists. All magnetic resonance imaging examinations were acquired with $1.5 \mathrm{~T}$ magnetic resonance imaging. Measurements were made by agreement between the two radiologists. The distance in $\mathrm{mm}$ was obtained in the axial plane at levels of $5 \mathrm{~cm}, 7.5 \mathrm{~cm}$, and $10 \mathrm{~cm}$ from the anal verge. Four readings were obtained at each level, namely, anterior, left lateral, posterior, and right lateral positions.

Results: A total of 25 patients (16 males, 9 females) with a median age of 69 (range, 38-84) years were included in the study. Mean thickness of the mesorectal fat at $5 \mathrm{~cm}, 7.5 \mathrm{~cm}$, and $10 \mathrm{~cm}$ from the anal verge was $3.1 \mathrm{~mm}$ (standard deviation, 3.0

This article was published on 1 Aug 2014 at www.hkmj.org. mesorectal fat thickness of $<15 \mathrm{~mm}$ were $100 \%, 84 \%$, and $75 \%$ at $5 \mathrm{~cm}, 7.5 \mathrm{~cm}$, and $10 \mathrm{~cm}$ from the anal verge, respectively. The thickness of mesorectal fat was the least anteriorly, and $<15 \mathrm{~mm}$ at all three arbitrary levels $(\mathrm{P}<0.001)$.

Conclusion: The thickness of mesorectal fat was $<15 \mathrm{~mm}$ in the majority of patients and in most positions. Tumours invading $10 \mathrm{~mm}$ beyond the serosa on magnetic resonance imaging may paradoxically threaten the circumferential resection margin in Chinese patients. Use of T3 subclassification of rectal cancer in Chinese patients may be limited.

\begin{tabular}{l} 
Hong Kong Med J 2014;20:366-70 \\
\hline DOI: 10.12809/hkmj144232 \\
${ }^{1}$ EMF Wong *, FHKCR, FHKAM (Radiology) \\
${ }^{1}$ BMH Lai, MB, BS, FRCR \\
${ }^{1}$ VKP Fung, MB, BS, FRCR \\
${ }^{2}$ HYS Cheung, FRACS, FHKAM (Surgery) \\
${ }^{3}$ WT Ng, FHKCR, FHKAM (Radiology) \\
${ }^{3}$ ALY Law, FHKCR, FHKAM (Radiology) \\
${ }^{1}$ AYT Lai, MB, BS \\
${ }^{1}$ JLS Khoo, FHKCR, FHKAM (Radiology) \\
${ }^{1}$ Department of Radiology \\
2 Department of Surgery \\
${ }^{3}$ Department of Oncology \\
Pamela Youde Nethersole Eastern Hospital, Chai Wan, Hong Kong \\
* Corresponding author: esthermfwong@gmail.com
\end{tabular}

New knowledge added by this study

- Paucity of mesorectal fat in Chinese populations: tumours invading $10 \mathrm{~mm}$ beyond the serosa on magnetic resonance imaging may threaten the circumferential resection margin in the majority of patients.

- The mesorectal fat is thinnest in the anterior portion. Tumours in the anterior wall have a higher chance of infiltrating the mesorectal fascia versus those located in other positions.

Implications for clinical practice or policy

- The T3 subclassification of rectal cancer should be used with caution in Chinese patients.

\section{Introduction}

Rectal cancer is associated with a high risk of distant metastases as well as local recurrence. The reported local recurrence rate after surgical treatment was up to $32 \%$ in some older literatures. ${ }^{1}$ Recently, magnetic resonance imaging (MRI) has emerged as a powerful local staging tool which also helps to guide subsequent management plan., ${ }^{2,3}$ The status of circumferential resection margin (CRM), presence of lymph node metastasis, and location of the tumour, all of which can be predicted on MRI, are important prognostic factors for pelvic disease recurrence after 
treatment with curative intent (local failure). ${ }^{4-6}$

The depth of extramural penetration of the tumour has been shown to be an independent prognostic factor. ${ }^{7}$ According to the European Society for Medical Oncology guidelines, ${ }^{8}$ T3 disease is subclassified into T3a, T3b, T3c, and T3d based on the depth of invasion beyond the muscularis propria (Table 1). Magnetic resonance imaging is also highly accurate in predicting the actual depth of this invasion. ${ }^{9}$ Currently, patients with disease more advanced than $\mathrm{T} 3 \mathrm{~b}$ are recommended to receive induction therapy prior to surgery.

Another factor that potentially affects the disease status is the thickness of the mesorectal fat which, for the sake of this discussion, shall be defined as the distance between the serosa and mesorectal fascia. The word 'perirectal fat' is used interchangeably with 'mesorectal fat'. We are of the opinion that the word 'mesorectal fat' better conceptualises compartmentalised fat within the mesorectal fascia and is, thus, selected for use in this article.

In our experience, the mesorectal fat is rather thin in Chinese patients. It is not uncommon to encounter early T3 $(\mathrm{T} 3 \mathrm{a} / \mathrm{b})$ disease with threatened CRM as predicted on MRI. The less the mesorectal fat thickness, the less the depth of extramural invasion it takes to infiltrate the CRM.

This study aimed to measure the amount of mesorectal fat in the local population. The use and limitation of T3 subclassification in the Chinese population will be discussed.

\section{Methods}

A total of 25 consecutive staging MRIs done for patients referred for rectal carcinoma multidisciplinary meetings at a local regional hospital from January to October 2012 were retrospectively reviewed by two radiologists with special interest in abdominal imaging.

All MRI examinations were acquired with 1.5T MRIs in two local centres using Siemens Magnetom Avanto (Erlangen, Germany) MRI machines. Measurements were made with mutual agreement between the two reviewing radiologists. The thickness of mesorectal fat was defined as the distance from the serosa to the mesorectal fascia in the axial plane. The distance in $\mathrm{mm}$ was obtained in the true axial plane at levels of $5 \mathrm{~cm}, 7.5 \mathrm{~cm}$, and

TABLE I. Subclassification of T3 rectal carcinoma

\begin{tabular}{cc}
\hline & Depth of invasion beyond muscularis propria (mm) \\
\hline T3a & $<1$ \\
T3b & $1-5$ \\
T3c & $6-15$ \\
T3d & $>15$ \\
\hline
\end{tabular}

\section{華籍患者中直腸系膜脂肪厚度不足導致直腸癌 T3期細分類的限制 \\ 黄文鳳、賴銘㬢、馮㤵邦、張睿珊、吳偉棠、羅麗柔、 黎爾德、邱麗珊}

目的：描述本地華籍人士直腸系膜脂肪的厚度及其對直腸癌分期的影 響。

設計：病例系列。

安排：香港兩間分區醫院。

患者：2012年1月至10月期間所有轉介至跨學科會議的病人。

主要結果測量：兩位放射科醫生替已進行分期磁共振成像並經病理學 證實為直腸癌的病例進行回顧和審查。所有成像均由 $1.5 \mathrm{~T}$ 磁共振成像 系統拍攝所得, 而所得結果均是兩人同意下所得。量度距離由肛門邊 緣在軸向平面上的 $5 \mathrm{~cm} 、 7.5 \mathrm{~cm}$ 和 $10 \mathrm{~cm}$ 的水平，並從以下四個位置 得出不同讀數：前側、左外側、後側和右外側。

結果：共25例（16男, 9女）被列入研究範圍, 病人年齡中位數 為69歲（介乎38至84歲）。從肛門邊緣 $5 \mathrm{~cm} 、 7.5 \mathrm{~cm}$ 和 $10 \mathrm{~cm}$ 所 量度到的直腸系膜脂肪厚度分別為 $3.1 \mathrm{~mm}$ (標準差, $3.0 \mathrm{~mm}$ )

$9.8 \mathrm{~mm}(5.3 \mathrm{~mm})$ 和 $11.8 \mathrm{~mm}(4.2 \mathrm{~mm})$ 。距離肛門邊緣 $5 \mathrm{~cm} 、 7.5 \mathrm{~cm}$ 和 $10 \mathrm{~cm}$ 所量度到平均少於 $15 \mathrm{~mm}$ 的直腸系膜脂肪厚度 的病人比例為 $100 \%$ 、 $84 \%$ 和 $75 \%$ 。前側的直腸系膜脂肪厚度最少, 而 另外三個水平均少於 $15 \mathrm{~mm}(\mathrm{P}<0.001)$

結論：多數患者在大多數位置上的直腸系膜脂肪厚度均少於 $15 \mathrm{~mm}$ 。 磁共振成像顯示腫瘤已侵入漿膜層 $10 \mathrm{~mm}$ 或影響華籍患者環週切緣的 情況。因此, 直腸癌 $\mathrm{T} 3$ 細分類在華籍患者中的用途可能有限。

$10 \mathrm{~cm}$ from the anal verge. Measurements were performed primarily on T2 sequence, supplemented by $\mathrm{T} 1$ sequence if the acquired $\mathrm{T} 2$ images were unsatisfactory. As this study involved two hospitals, the scanning parameter was not identical. However, such difference was not assumed to attribute to error

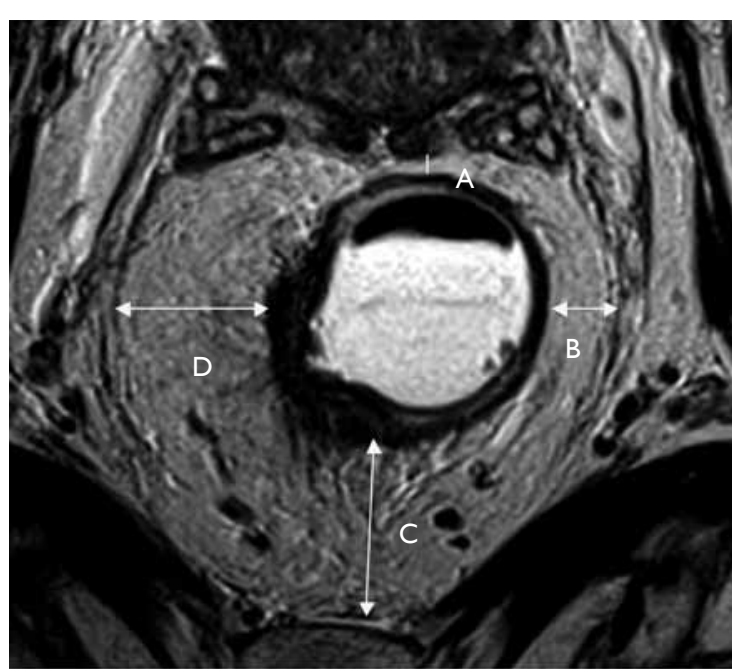

FIG I. Thickness of mesorectal fat is measured at anterior $(A)$, left lateral $(B)$, posterior $(C)$, and right lateral (D) positions 
of any source in terms of calibre measurement.

Four readings were obtained at each level, namely, anterior, left lateral, posterior, and right lateral positions (Fig 1).

Patients with bulky primary or secondary pelvic tumours ( $>3 \mathrm{~cm}$ in diameter) were excluded from the study, as these might potentially cause significant distortion of the anatomy and configuration of the mesorectum.

Statistical analysis was performed with the Statistical Package for the Social Sciences (Windows version 15.0; SPSS Inc, Chicago [IL], US). Onesample Student's $t$ test was performed for analysis of mean thickness.

\section{Results}

A total of 25 patients (16 males, 9 females) with a median age of 69 (range, 38-84) years were included in the study. The rectosigmoid junctions were reached at the level of $10 \mathrm{~cm}$ above the anal verge for four patients and were, thus, excluded from calculation for the respective level.

Mean thicknesses of mesorectal fat at $5 \mathrm{~cm}$, $7.5 \mathrm{~cm}$, and $10 \mathrm{~cm}$ from the anal verge were 3.1 (standard deviation $[\mathrm{SD}]=3.0) \mathrm{mm}, 9.8 \quad(\mathrm{SD}=5.3)$ $\mathrm{mm}$, and $11.8(\mathrm{SD}=4.2) \mathrm{mm}$, respectively. Details of the mean mesorectal fat thickness are shown in Table 2. In brief, the proportions of patients with mean mesorectal fat thickness of $<15 \mathrm{~mm}$ were $100 \%, 84 \%$, and $75 \%$ at $5 \mathrm{~cm}, 7.5 \mathrm{~cm}$, and $10 \mathrm{~cm}$ from the anal verge, respectively.

The mesorectal fat was noted to be the least thick in the anterior position for all three arbitrary levels (Table 2; Fig 2). At $5 \mathrm{~cm}$ and $7.5 \mathrm{~cm}$ from the

TABLE 2. Variation of mesorectal fat thickness with position

\begin{tabular}{|c|c|c|c|}
\hline \multirow[t]{2}{*}{ Position } & \multicolumn{3}{|c|}{ Levels (distance from anal verge) } \\
\hline & $5 \mathrm{~cm}$ & $7.5 \mathrm{~cm}$ & $10 \mathrm{~cm}$ \\
\hline \multicolumn{4}{|l|}{ Mean thickness of mesorectal fat (mm) } \\
\hline Anterior & 1.0 & 3.0 & 3.7 \\
\hline Left lateral & 3.9 & 14.7 & 14.5 \\
\hline Posterior & 2.6 & 9.8 & 13.8 \\
\hline Right lateral & 4.9 & 12.4 & 12.9 \\
\hline Average (anterior + left lateral + posterior + right lateral / 4 ) & 3.1 & 9.8 & 11.8 \\
\hline Patients with mean thickness $<5 \mathrm{~mm}$ & $80 \%(n=20)$ & $20 \%(n=5)$ & $10 \%(n=2)$ \\
\hline Patients with mean thickness $<15 \mathrm{~mm}$ & $100 \%(n=25)$ & $84 \%(n=21)$ & $75 \%(n=15)$ \\
\hline
\end{tabular}

TABLE 3. Thickness of anterior mesorectal fat with respective $P$ values

\begin{tabular}{|c|c|c|c|c|}
\hline Distance from anal verge & $\begin{array}{l}\text { Proportion of patients with } \\
\text { thickness }<5 \mathrm{~mm}\end{array}$ & P value* & $\begin{array}{c}\text { Proportion of patients with } \\
\text { thickness }<15 \mathrm{~mm}\end{array}$ & $\mathrm{P}$ value \\
\hline $5 \mathrm{~cm}$ & $96 \%$ & $<0.001$ & $100 \%$ & $<0.001$ \\
\hline $7.5 \mathrm{~cm}$ & $88 \%$ & 0.01 & $100 \%$ & $<0.001$ \\
\hline $10 \mathrm{~cm}$ & $71 \%$ & 0.15 & $95 \%$ & $<0.001$ \\
\hline
\end{tabular}

* $\mathrm{P}<0.05$ indicates mean anterior mesorectal thickness significantly $<5 \mathrm{~mm}$

† $P<0.05$ indicates mean anterior mesorectal thickness significantly $<15 \mathrm{~mm}$
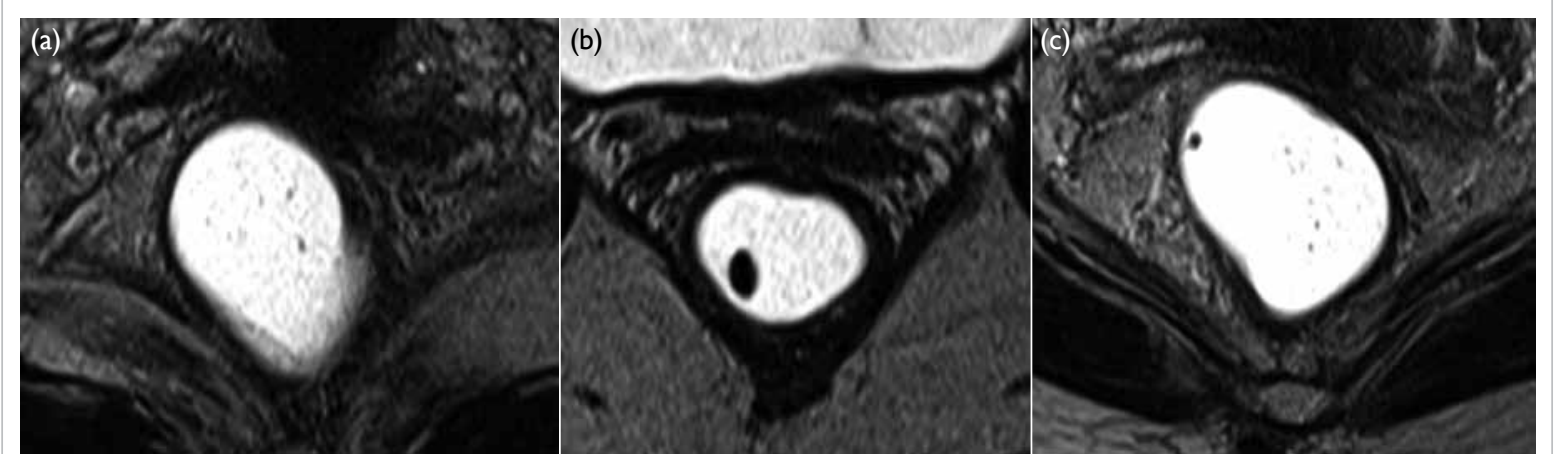

FIG 2. A patient with marked paucity of mesorectal fat.T2 axial images obtained at (a) $5 \mathrm{~cm}$, (b) $7.5 \mathrm{~cm}$, and (c) $10 \mathrm{~cm}$ from the anal verge. The mesorectal fat is thinnest at its anterior aspect at all levels 
anal verge, proportions of patients with mesorectal fat thickness of $<5 \mathrm{~mm}$ were $96 \%$ and $88 \%$, respectively. The figure reached up to $100 \%$ if $15 \mathrm{~mm}$ was taken as the cutoff level. At $10 \mathrm{~cm}$ from the anal verge, 95\% of patients showed mesorectal fat thickness of $<15 \mathrm{~mm}$. $t$ Tests showed that the anterior mesorectal fat thickness was significantly $<15 \mathrm{~mm}$ at all three levels $(\mathrm{P}<0.001)$ and $<5 \mathrm{~mm}$ at both $5 \mathrm{~cm}(\mathrm{P}<0.001)$ and $7.5 \mathrm{~cm}(\mathrm{P}=0.01)$ from the anal verge (Table 3$)$.

There was a tendency for the lateral aspects to be more spacious than the anterior and posterior aspects, and for the left side to be larger than the right side. However, these findings were not statistically significant.

\section{Discussion}

To the best of our knowledge, this is the first Chinese study and the first study in Asian subjects on mesorectal fat thickness. The majority of published literature on MRI staging of carcinoma of rectum are based, predominantly, on data from western/Caucasian populations. It has been well known that variations in body build, lean mass, and fat composition do occur across ethnic groups. ${ }^{10}$ Chinese or Asian patients have a smaller body build. Whether the amount of fat in the mesorectum is the same in Chinese and Caucasian population remains largely unknown.

In recent decades, total mesorectal excision has revolutionised rectal cancer surgery. ${ }^{11}$ Patients with relatively early tumours (ie T3b or below, lymph node-negative) are usually streamlined to total mesorectal excision without preoperative neoadjuvant therapy. The rationale behind this is that early, mid- and low-rectal tumours with their whole lymphatic drainage are contained within the mesorectal fascia. Total mesorectal excision allows en-bloc removal of the tumour together with its intact mesorectal fascia. A low local recurrence rate of only $4 \%$ has been reported. ${ }^{12}$

An involved CRM is an independent disease prognostic indicator. ${ }^{13}$ It is defined pathologically as identifying tumour cells within $1 \mathrm{~mm}$ of the surgically created margin. Beets-Tan et $\mathrm{al}^{14}$ postulated that, on MRI, a distance of $6 \mathrm{~mm}$ from the outer edge of the tumour to the mesorectal fascia predicted a tumour distance of $2 \mathrm{~mm}$ on histology with $97 \%$ confidence, and a distance of $5 \mathrm{~mm}$ could predict a crucial distance of $1 \mathrm{~mm}$ on histology with high confidence. A study using $1 \mathrm{~mm}$ as cutoff showed data with satisfactory accuracy despite a lower sensitivity. ${ }^{15}$ For practical purposes, we have adopted a cutoff of $5 \mathrm{~mm}$ as the predictor of clear CRM.

Given a certain depth of tumour invasion, CRM is more likely to be threatened for patients with thinner mesorectal fat (Fig 3). The mean thickness of mesorectal fat is $<15 \mathrm{~mm}$ for the majority of patients at all arbitrarily measured levels. Taking

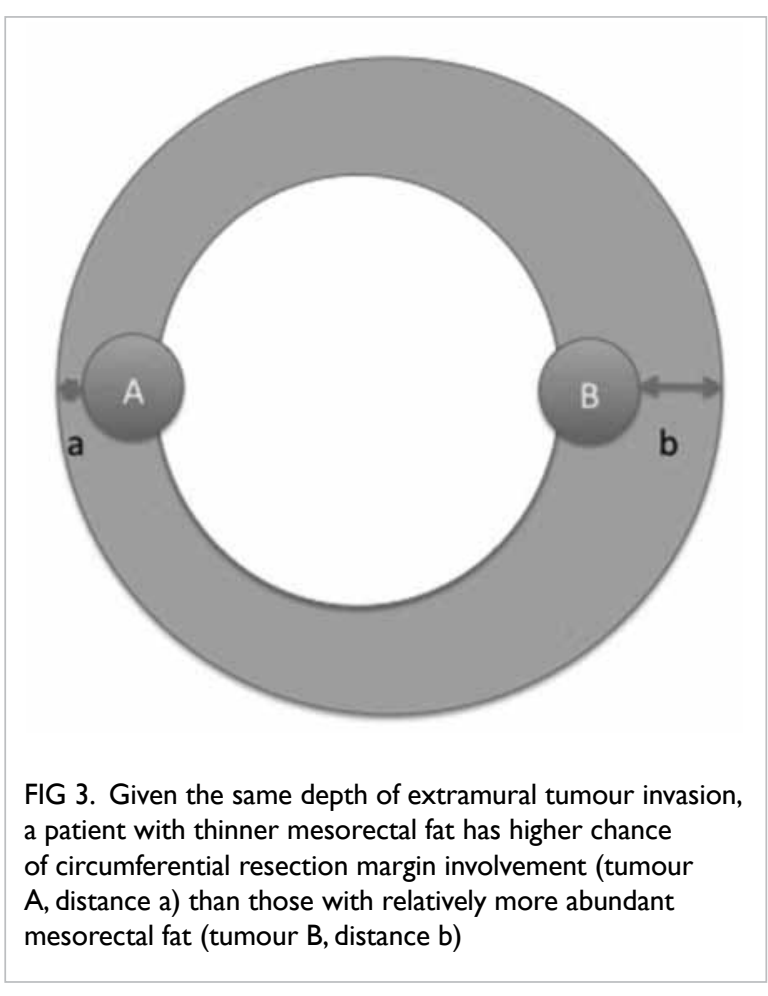

into account the margin of $5 \mathrm{~mm}$ on MRI, a tumour invading $10 \mathrm{~mm}$ beyond the serosa on MRI fulfils the criteria for threatened CRM in the majority of patients. Whether Chinese patients present with later-stage disease or have worse disease prognosis is largely unknown. However, caution has to be taken that $\mathrm{T} 3 \mathrm{a} / \mathrm{b}$ disease in Chinese populations does not equal, or even imply, early-stage disease.

The position of the tumour may also affect the chance of mesorectal fat infiltration. The anterior aspect of the mesorectal fat was found to be thinnest at all three arbitrary levels. This is in agreement with studies in European populations. ${ }^{16}$ The postulated reason is that the anterior mesorectal fat tends to be compressed by anterior pelvic organs such as the uterus and prostate when one lies in supine position, the position where MRI is conventionally acquired. As a result, anterior tumour tends to threaten the CRM with relatively shallow subserosal penetration.

The mesorectal fat is thinner inferiorly as it approaches the anal verge. Low rectal cancer $(<5 \mathrm{~cm}$ from the anal verge) has overall worse prognosis. Higher local recurrence rate with higher chances of CRM involvement has been reported. ${ }^{17}$ This may be partly explained by the fact that the amount of mesorectal fat is thinner in low rectum. Low rectal tumours also deserve special surgical attention. ${ }^{18}$

One major weakness of this study was that body mass index (BMI) was not taken into account. However, a study in the UK ${ }^{19}$ has shown that BMI does not affect the thickness or volume of mesorectal 
fat. However, the measurement method employed in that study was different from that in our study, rendering direct comparison difficult. Whether the paucity of mesorectal fat in Chinese patients is due to body build or genetic factors is unknown. Further multicentre studies with collection of BMI data and ethnic information and using standardised measurement methods are needed for better comparison.

\section{Conclusion}

Thickness of mesorectal fat is shown to be $<15 \mathrm{~mm}$ in the majority of patients in most positions and at most levels. It was $<5 \mathrm{~mm}$ for low rectal position. T3a/b tumours may paradoxically infiltrate the mesorectal fascia in the study population. In staging of Chinese rectal cancer patients, $\mathrm{T} 3 \mathrm{a} / \mathrm{b}$ tumours may threaten the CRM in the majority of locations and patients. Thus, the status of $\mathrm{T} 3 \mathrm{a} / \mathrm{b}$ alone should not be taken as an indicator of early-stage disease.

\section{Acknowledgements}

We would like to acknowledge Dr John KW Chan and St Paul's Hospital for courtesy of MRI images.

\section{References}

1. Sagar PM, Pemberton JH. Surgical management of locally recurrent rectal cancer. Br J Surg 1996;83:293-304.

2. Beets-Tan RG, Beets GL. Rectal cancer: review with emphasis on MR imaging. Radiology 2004;232:335-46.

3. Bipat S, Glas AS, Slors FJ, Zwinderman AH, Bossuyt PM, Stoker J. Rectal cancer: local staging and assessment of lymph node involvement with endoluminal US, CT, and MR imaging-a meta-analysis. Radiology 2004;232:773-83.

4. Pedersen BG, Moran B, Brown G, Blomqvist L, FengerGrøn M, Laurberg S. Reproducibility of depth of extramural tumor spread and distance to circumferential resection margin at rectal MRI: enhancement of clinical guidelines for neoadjuvant therapy. AJR Am J Roentgenol 2011;197:1360-6.

5. van Gijn W, Marijnen CA, Nagtegaal ID, et al. Preoperative radiotherapy combined with total mesorectal excision for resectable rectal cancer: 12-year follow-up of the multicentre, randomised controlled TME trial. Lancet Oncol 2011;12:575-82.

6. Lahaye MJ, Engelen SM, Nelemans PJ, et al. Imaging for predicting the risk factors-the circumferential resection margin and nodal disease-of local recurrence in rectal cancer: a meta-analysis. Semin Ultrasound CT MR 2005;26:259-68.

7. Shin R, Jeong SY, Yoo HY, et al. Depth of mesorectal extension has prognostic significance in patients with T3 rectal cancer. Dis Colon Rectum 2012;55:1220-8.

8. Glimelius B, Tiret E, Cervantes A, Arnold D; ESMO Guidelines Working Group. Rectal cancer: ESMO Clinical Practice Guidelines for diagnosis, treatment and follow-up. Ann Oncol 2013;24 Suppl 6:vi81-8.

9. MERCURY Study Group. Extramural depth of tumor invasion at thin-section MR in patients with rectal cancer: results of the MERCURY study. Radiology 2007;243:132-9.

10. Lear SA, Kohli S, Bondy GP, Tchernof A, Sniderman AD. Ethnic variation in fat and lean body mass and the association with insulin resistance. J Clin Endocrinol Metab 2009;94:4696-702.

11. Heald RJ, Ryall RD. Recurrence and survival after total mesorectal excision for rectal cancer. Lancet 1986;327:1479-82.

12. Heald RJ, Moran BJ, Ryall RD, Sexton R, MacFarlane JK. Rectal cancer: the Basingstoke experience of total mesorectal excision, 1978-1997. Arch Surg 1998;133:8949.

13. Bernstein TE, Endreseth BH, Romundstad P, Wibe A; Norwegian Colorectal Cancer Group. Circumferential resection margin as a prognostic factor in rectal cancer. $\mathrm{Br}$ J Surg 2009;96:1348-57.

14. Beets-Tan RG, Beets GL, Vliegen RF, et al. Accuracy of magnetic resonance imaging in prediction of tumourfree resection margin in rectal cancer surgery. Lancet 2001;357:497-504.

15. MERCURY Study Group. Diagnostic accuracy of preoperative magnetic resonance imaging in predicting curative resection of rectal cancer: prospective observational study. BMJ 2006;333:779.

16. Torkzad MR, Blomqvist L. The mesorectum: morphometric assessment with magnetic resonance imaging. Eur Radiol 2005;15:1184-91.

17. Nagtegaal ID, van de Velde CJ, Marijnen CA, van Krieken JH, Quirke P; Dutch Colorectal Cancer Group; Pathology Review Committee. Low rectal cancer: a call for a change of approach in abdominoperineal resection. J Clin Oncol 2005;23:9257-64.

18. Salerno G, Daniels IR, Brown G. Magnetic resonance imaging of the low rectum: defining the radiological anatomy. Colorectal Dis 2006;8 Suppl 3:10-3.

19. Allen SD, Gada V, Blunt DM. Variation of mesorectal volume with abdominal fat volume in patients with rectal carcinoma: assessment with MRI. Br J Radiol 2007;80:2427. 